\title{
Mating system of yellow starthistle (Centaurea solstitialis), a successful colonizer in North America
}

\author{
MEI SUN* \& KERMIT RITLAND+ \\ Department of Botany and Zoology, University of Hong Kong, Pokfulam Road, Hong Kong and †Department of \\ Forest Sciences, 2357 Main Mall, University of British Columbia, Vancouver, BC, Canada V6T1Z4
}

\begin{abstract}
The mating system of Centaurea solstitialis L. was investigated in relation to its colonization of North America. A preliminary investigation of its reproductive biology suggested that the species is a pollinator-dependent outbreeder, and probably self-incompatible. Quantitative analysis of the mating system parameters was performed using progeny arrays assayed for nine allozyme markers. Multilocus outcrossing rates $\left(t_{\mathrm{m}}\right)$ ranged from 0.948 to 0.990 among eight populations. Moderate levels of biparental inbreeding ( $\approx 6$ per cent apparent selfing) were detected in most populations. The correlation of outcrossed paternity within progeny arrays $\left(r_{\mathrm{p}}\right)$ ranged from 0.05 to 0.64 among populations, indicating differences in modes of outcross pollination. A geographically marginal population, San Diego, showed the only significant parental inbreeding coefficient $(F=0.27)$, as well as highest $r_{\mathrm{p}}$, suggesting microevolutionary changes of mating system following founder events. One other population exhibited significant variation of individual plant outcrossing rate, with a correlation of selfing within progeny arrays of $r_{\mathrm{s}}=0.65$, indicating variation of self-incompatibility. Mating system variation in colonizing, self-incompatible species is valuable for understanding the evolution of self-incompatibility systems.
\end{abstract}

Keywords: Centaurea solstitialis, colonizing species, mating system, self-fertilization.

\section{Introduction}

Reproduction is the fundamental challenge in the establishment of colonizing populations (Baker, 1955). The mating system has long been recognized as playing an important role in plant colonization, with a predominance of uniparental reproduction in colonizers (Baker \& Stebbins, 1965; Brown \& Burdon, 1987). This, and the associated occurrence of bottlenecks of population size, profoundly affects the genetic diversity and structure of colonizing populations, and their capacity to respond to local selection pressures (Hamrick et al., 1979).

The mating systems of many successful colonizers have been inferred from their reproductive features (Fryxell, 1957), and such features are associated with colonization success (Brown \& Marshall, 1981). Genetic marker analysis can provide more accurate and detailed information on the mating system parameters. Marker-based estimates of mating systems

*Correspondence. E-mail: meisun@hkucc.hku.hk have been conducted for only a few successful colonizers (Glover \& Barrett, 1986; Burdon et al., 1988; Sun \& Corke, 1992; Abbott \& Forbes, 1993). Such inferences can provide new perspectives; local variation of mating system parameters provides insights into environmental factors affecting the mating system, and differences between central and marginal populations for mating system parameters indicate microevolutionary changes following founder events.

The mating system has traditionally been characterized by selfing rates, which influence patterns of population genetic structure. When patterns of paternity are also included as facets of the mating system, the genetic relatedness among progeny of a plant becomes relevant. The pattern of paternity can be measured by parameters of the 'correlated mating model' of Ritland (1989). One parameter is the correlation of outcrossed paternity within progeny arrays, $r_{\mathrm{p}}$ (alternatively, the proportion of pairs of progeny which are full-sibs, as opposed to half-sibs; see Ritland, 1989). This correlation arises 
from repeated matings to the same near-neighbours, or from the tendency of pollinator pollen loads to be derived from single plants. In partially selfing populations, correlations among progeny also arise from variation of selfing rates among plants. This is measured by a second parameter, the correlation of selfing within progeny arrays, $r_{\mathrm{s}}$ (Ritland, 1989). In general, correlations among sibs affect local patterns of genetic variation, and the effectiveness of local selection.

Centaurea solstitialis L. (yellow starthistle) is a diploid $(2 n=16)$, herbaceous annual of Eurasian origin. Since its accidental introduction to California in the mid-19th century, probably as a contaminant in alfalfa seed, the species has become a naturalized weed of wide distribution and serious economic impact (Maddox \& Mayfield, 1985; Maddox et al., 1985). It frequently invades a variety of disturbed habitats, such as parks and rangelands, pastures, hayfields, orchards, vineyards, roadsides and irrigation banks (Robbins et al., 1951; Thomsen et al., 1994). Previous and ongoing research has concentrated on ecological studies in relation to management and biological control (Thomsen et al., 1989; Maddox et al., 1991; Roche, 1991; Callihan et al., 1993). Little is known about the mating system and population genetics of this species.

In this study, mating system parameters of $C$. solstitialis were estimated, and variation in these parameters assessed in relation to the colonization of North America by this species. Geographically marginal populations were compared with central populations to determine if colonization of marginal sites has led to changes in mating system parameters. Information on the mating system parameters of this species will also help explain the patterns of genetic diversity in North American populations of C. solstitialis.

\section{Materials and methods}

A preliminary pollinator-exclusion experiment was conducted within a fenced area at the Agronomy Farm of the University of California, Davis. Eighteen plants at reproductive stage, at least $2 \mathrm{~m}$ apart, were used. One to three preanthesis flower heads per plant were covered with a semitransparent, waterproof paper bag; other flower heads at a similar developmental stage on the same plant were used as controls (open-pollinated). After five to six weeks, these flower heads were harvested, the numbers of florets and seeds were counted, and percentages seed-set for the bagged and open-pollinated heads were determined.
Eight natural populations were sampled in 1995 for mating system studies. These populations were Airport, Davis II and San Diego from California; Asotin, Gold Hill, Klickitat and Walla Walla from Washington; and Lenore from Idaho (see Sun, 1997 for site information). They were selected on the basis of regional representation: Davis II and Airport represent populations in the Sacramento Valley area, where yellow starthistle's invasion is particularly prominent; San Diego represents the southern extreme of the distribution in California; Lenore represents an old invasion in Idaho; and the four populations of Washington came from areas with well-recorded histories of colonization from 1900 to the present; Gold Hill also represents the northern extreme of colonization.

On average, 12 seeds per plant and 40 plants per population were germinated to generate progeny arrays used in mating system analyses. Nine polymorphic allozyme loci were used as gene markers: Aco-1, Aco-2, Alp-2, Dia-2, Lap-1, Pgm-1, Pgm-2, Pgi-2 and Skdh-1. Details of electrophoretic procedures are given elsewhere (Sun, 1997). Singlelocus, Mendelian inheritance at these loci was verified by the conformity of progeny array patterns to Mendelian predictions, a useful method when controlled crosses are not available (Kephart, 1990). Specifically, one maternal allele was always found in each progeny (no families showed more than two alternative homozygotes, and genotypes of $a a$ and $b b$ were not found with $c d$ within the same family). In addition, these loci have been assayed in a large number of organisms (Kephart, 1990) and generally shown to follow Mendelian ratios.

Mating system parameters were estimated using the MLTR program (available from K. Ritland). The program calculates maximum likelihood estimates of both outcrossing rates (based on the model of Ritland \& Jain, 1981) and correlated mating parameters (based on the correlated matings model of Ritland, 1989; see above). The mating system parameters estimated included: the multilocus population outcrossing rate $t_{\mathrm{m}}$, the average single-locus population outcrossing rate $t_{\mathrm{s}}$, the inbreeding coefficient of maternal parents $F$, the correlated selfing rate $r_{\mathrm{s}}$, and the correlation of paternal genotypes between outcrossed sibs $r_{\mathrm{p}}$.

Because pollen and ovule population allele frequencies did not differ significantly, they were pooled to increase statistical power for estimating mating system parameters. For populations with significant correlated selfing, individual-plant multilocus outcrossing estimates were obtained. The Newton-Raphson method was used to find the 
maximum likelihood estimates. Standard errors of population estimates, including $t_{\mathrm{m}}-t_{\mathrm{s}}$, were calculated using 100 bootstraps, where the unit of resampling was the progeny array. When several parameters are simultaneously estimated, the potential exists for nonconvergence of the estimates to the true maximum, because of ridges and possibly minor peaks. Although the data have sufficient degrees of freedom for all parameters (Ritland, 1989), the $r_{\mathrm{s}}$ vs. $r_{\mathrm{p}}$ surface will have a ridge (see fig. 3 in Ritland, 1989), reflecting their negative statistical correlation, and iterations can stall on this ridge if it is sufficiently flat. However, the use of more variable markers, as in this study, minimizes this problem (see fig. 2 in Ritland, 1989). Other parameters of the model are much more statistically independent, implying easier joint numerical maximization. At least, the method of bootstrapping is expected to incorporate errors caused by inaccurate numerical maximization of the likelihood function.

\section{Results}

The bagging experiment showed that seed-set is pollinator-dependent: only one of 18 bagged flower heads (capitula) set seed, and it produced only three mature seeds. Unbagged (control) capitula on the same plant always set seed, with an average of 53 seeds each, but some florets within a capitulum did not set seed. The presence of just one ovule per floret gave a seed/ovule ratio for these fertile controls of 0.74 seeds per ovule in contrast to 0.0016 for the bagged capitula. The number of florets per capitulum in the sample ranged from 56 to 100 , averaging 75 .

Nine enzyme loci were polymorphic in the eight populations (Table 1) and quite high levels of variation were often found, with two to six alleles per locus, and triallelism quite common. Estimates of allele frequencies for maternal parents differed from those for the pollen pool only 13 of 222 times at the 5 per cent level, which is about that expected by chance. For this reason, the two gene pools were combined for subsequent estimations.

All populations showed a predominant outcrossing. Multilocus outcrossing rates ranged from 0.948 $(\mathrm{SE}=0.039)$ in San Diego to $0.990(0.015)$ in Davis II, with a mean of $0.978(0.007)$ for the eight populations (Table 2). Despite the high multilocus population outcrossing rates, genetic substructuring may exist in these populations, leading to some degree of biparental inbreeding. This inbreeding is detected by the difference between multilocus and single-locus selfing rates, as the latter include biparental inbreed- ing (Ritland \& Jain, 1981). Indeed, significant differences between $t_{\mathrm{m}}$ and $t_{\mathrm{s}}$ were found in nearly all populations, ranging from 0.007 to 0.122 , with an average of 0.057 . A significantly positive parental inbreeding coefficient was found only in the marginal population, San Diego, where $F=0.270$.

The correlation of paternity (probability that sibs shared the same father) ranged from $r_{\mathrm{p}}=0.047$ to 0.636 , with a mean of 0.189 in these populations (Table 2). The average 'paternal mating pool' was 5-6 plants (Table 2), with the extremes found in San Diego (1-2 plants) and Airport (21-22 plants). This 'pool' is calculated as the inverse of $r_{\mathrm{p}}$ (Ritland, 1989) and is the number of males that gives rise to this correlation, assuming all males have equal mating probabilities and consecutive matings are independent (Ritland, 1989). If the observed correlation is low, this pool may be larger than the size of the progeny array (in fact, a desirable feature of this statistic is that it is independent of the progeny array sample size). Individual plant estimates revealed significant correlation of selfing (among-plant variation of outcrossing rate) only within the Asotin population (Table 2). A plot of individual outcrossing rates for this population indicates that this correlation probably arises from a few families exhibiting significant selfing (Fig. 1).

\section{Discussion}

Because colonization frequently involves a small number of founders, a self-incompatibility system is generally disadvantageous for colonizing species, as often no compatible mates are available. Selfcompatibility assures reproduction (Baker's rule; Baker, 1955) and, furthermore, allows uniparental reproduction which is not dependent upon pollinators, and which may also rapidly generate and maintain adaptive genotypes following successful establishment (Stebbins, 1957). Outbreeding species are often successful colonizers (Brown \& Marshall, 1981), but nearly all are self-compatible. The rare cases of self-incompatible colonizers provide an opportunity to examine the genetics and selective pressures underlying self-incompatibility (Barrett \& Richardson, 1985).

\section{Self-incompatibility and reproductive success}

The nearly complete outcrossing in most populations of $C$. solstitialis studied here supports the finding of Maddox et al. (1996) that the species is predominantly self-incompatible. A plant will simultaneously produce many flower heads and many florets per 


(1)

\begin{tabular}{|c|c|c|c|c|c|c|c|c|c|}
\hline \multicolumn{2}{|c|}{ Locus/allele } & \multirow{2}{*}{$\begin{array}{c}\text { Airport } \\
0.331(0.033)\end{array}$} & \multirow{2}{*}{$\frac{\text { Davis II }}{0.428(0.028)}$} & \multirow{2}{*}{$\frac{\text { San Diego }}{0.340(0.036)}$} & \multirow{2}{*}{$\begin{array}{c}\text { Asotin } \\
0.041(0.013)\end{array}$} & \multirow{2}{*}{$\begin{array}{c}\text { Gold Hill } \\
0.451(0.031)\end{array}$} & \multirow{2}{*}{$\begin{array}{c}\text { Klickitat } \\
0.286(0.028)\end{array}$} & \multirow{2}{*}{$\begin{array}{l}\text { Walla Walla } \\
0.176(0.015)\end{array}$} & Lenore \\
\hline Pgm-1 & $a$ & & & & & & & & - \\
\hline Pgm-1 & $b$ & $0.583(0.033)$ & $0.357(0.026)$ & $0.660(0.036)$ & $0.597(0.030)$ & $0.285(0.032)$ & $0.603(0.038)$ & $0.773(0.017)$ & - \\
\hline Pgm-1 & $c$ & $0.085(0.017)$ & $0.215(0.022)$ & $0.000(0.000)$ & $0.362(0.031)$ & $0.264(0.034)$ & $0.099(0.023)$ & $0.051(0.011)$ & $-\quad-$ \\
\hline Pgm-2 & $a$ & $0.199(0.022)$ & $0.151(0.016)$ & $0.000(0.000)$ & $0.006(0.003)$ & $0.252(0.021)$ & $0.303(0.030)$ & $0.337(0.024)$ & $0.042(0.011)$ \\
\hline Pgm-2 & $b$ & $0.555(0.027)$ & $0.711(0.025)$ & $0.792(0.027)$ & $0.594(0.026)$ & $0.643(0.025)$ & $0.654(0.034)$ & $0.473(0.026)$ & $0.591(0.035)$ \\
\hline Pgm-2 & $c$ & $0.246(0.028)$ & $0.138(0.022)$ & $0.208(0.027)$ & $0.400(0.026)$ & $0.105(0.015)$ & $0.043(0.015)$ & $0.191(0.020)$ & $0.367(0.035)$ \\
\hline Lap-1 & $b$ & $0.150(0.015)$ & $0.043(0.008)$ & $0.000(0.000)$ & $0.203(0.025)$ & $0.201(0.021)$ & $0.208(0.028)$ & $0.111(0.011)$ & $0.155(0.023)$ \\
\hline Lap-1 & $c$ & $0.137(0.021)$ & $0.081(0.013)$ & $0.000(0.000)$ & $0.090(0.013)$ & $0.257(0.027)$ & $0.097(0.025)$ & $0.316(0.027)$ & $0.148(0.017)$ \\
\hline Lap-1 & $d$ & $0.332(0.032)$ & $0.428(0.023)$ & $0.942(0.009)$ & $0.499(0.032)$ & $0.261(0.030)$ & $0.358(0.033)$ & $0.097(0.015)$ & $0.220(0.024)$ \\
\hline Lap-1 & $e$ & $0.101(0.017)$ & $0.093(0.018)$ & $0.055(0.008)$ & $0.055(0.011)$ & $0.018(0.006)$ & $0.086(0.017)$ & $0.145(0.016)$ & $0.160(0.030)$ \\
\hline Lap-1 & $f$ & $0.237(0.030)$ & $0.278(0.027)$ & $0.003(0.002)$ & $0.061(0.010)$ & $0.244(0.020)$ & $0.213(0.025)$ & $0.246(0.016)$ & $0.155(0.022)$ \\
\hline Skdh-1 & $a$ & $0.211(0.021)$ & $0.202(0.020)$ & $0.589(0.038)$ & $0.233(0.029)$ & $0.136(0.018)$ & $0.208(0.018)$ & $0.365(0.022)$ & $0.043(0.013)$ \\
\hline Skdh-1 & $b$ & $0.768(0.021)$ & $0.728(0.023)$ & $0.407(0.039)$ & $0.482(0.021)$ & $0.864(0.018)$ & $0.764(0.019)$ & $0.612(0.021)$ & $0.676(0.033)$ \\
\hline Skdh-1 & $c$ & $0.021(0.007)$ & $0.060(0.011)$ & $0.004(0.002)$ & $0.283(0.026)$ & $0.000(0.000)$ & $0.028(0.010)$ & $0.023(0.006)$ & $0.281(0.027)$ \\
\hline$P g i-2$ & $b$ & $0.969(0.007)$ & $0.938(0.011)$ & $0.995(0.001)$ & $0.997(0.000)$ & $0.997(0.001)$ & $0.966(0.008)$ & $0.979(0.005)$ & $0.990(0.003)$ \\
\hline Aco-1 & $a$ & $0.278(0.027)$ & $0.159(0.038)$ & $0.699(0.048)$ & $0.016(0.007)$ & $0.069(0.012)$ & $0.099(0.013)$ & $0.143(0.017)$ & $0.004(0.001)$ \\
\hline Aco-1 & $b$ & $0.702(0.030)$ & $0.802(0.040)$ & $0.301(0.048)$ & $0.898(0.013)$ & $0.784(0.018)$ & $0.837(0.023)$ & $0.778(0.016)$ & $0.945(0.010)$ \\
\hline Aco-1 & $c$ & $0.019(0.013)$ & $0.040(0.010)$ & $0.000(0.000)$ & $0.087(0.013)$ & $0.147(0.014)$ & $0.064(0.019)$ & $0.079(0.008)$ & $0.052(0.010)$ \\
\hline Aco-2 & $b$ & $0.898(0.015)$ & $0.910(0.015)$ & $0.995(0.001)$ & $0.997(0.000)$ & $0.960(0.012)$ & $0.861(0.020)$ & $0.990(0.003)$ & $0.992(0.004)$ \\
\hline Alp-2 & $a$ & $0.624(0.032)$ & $0.716(0.032)$ & $0.724(0.030)$ & $0.526(0.046)$ & $0.246(0.026)$ & $0.485(0.029)$ & $0.399(0.022)$ & $0.317(0.028)$ \\
\hline Alp-2 & $b$ & $0.034(0.010)$ & $0.024(0.009)$ & $0.005(0.001)$ & $0.340(0.045)$ & $0.003(0.000)$ & $0.004(0.003)$ & $0.062(0.012)$ & $0.004(0.000)$ \\
\hline Alp-2 & $c$ & $0.331(0.033)$ & $0.260(0.028)$ & $0.272(0.030)$ & $0.135(0.022)$ & $0.751(0.026)$ & $0.505(0.029)$ & $0.540(0.020)$ & $0.319(0.042)$ \\
\hline Dia-2 & $a$ & $0.536(0.041)$ & $0.534(0.057)$ & $0.147(0.022)$ & $0.672(0.040)$ & $0.564(0.027)$ & $0.494(0.038)$ & $0.752(0.031)$ & $0.617(0.020)$ \\
\hline Dia-2 & $b$ & $0.281(0.026)$ & $0.197(0.075)$ & $0.115(0.038)$ & $0.074(0.020)$ & $0.409(0.029)$ & $0.366(0.023)$ & $0.243(0.031)$ & $0.029(0.012)$ \\
\hline Dia-2 & $c$ & $0.160(0.031)$ & $0.269(0.069)$ & $0.737(0.044)$ & $0.254(0.040)$ & $0.024(0.009)$ & $0.131(0.030)$ & $0.002(0.000)$ & $0.354(0.025)$ \\
\hline
\end{tabular}




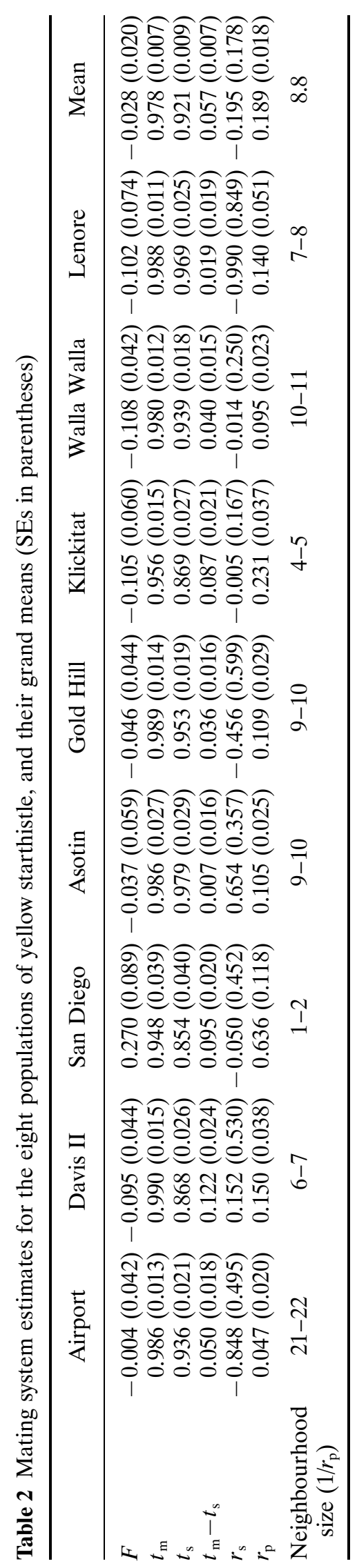

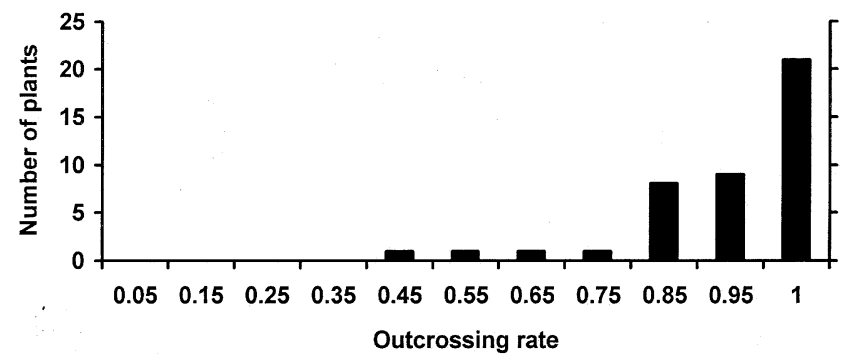

Fig. 1 Distribution of outcrossing rates in the Asotin population of yellow starthistle.

head concurrently at anthesis, and bees often visit several flower heads on a single plant (M. Sun, pers. obs.). High levels of outcrossing occur despite this potential for geitonogamous selfing.

How do colonizing populations overcome the limitation of self-incompatibility and achieve reproductive success? The following factors could be involved: (i) human-mediated migration involving large numbers of seeds; (ii) extended reproductive periods and nonspecialized pollinator requirements; (iii) massive seed production; and (iv) occasional breakdown of self-incompatibility or temporary reversals to self-compatibility (Pandey, 1980; Barrett, 1988).

The wind-assisted dispersal of the pappus-bearing seeds in C. solstitialis is not sufficient for longdistance dispersal (Roche, 1991). Anthropogenic factors, such as man-mediated migrations through transportation of contaminated hay or crop seeds, must have frequently been involved in the spread of this species throughout North America. These introductions probably involved many founders. One other factor limiting reproduction in a self-incompatible species is availability of pollinators at newly colonized sites. Like many species of Compositae, yellow starthistle flowers have a nonspecialized pollination mechanism involving generalist insects. Honeybees (Apis mellifera L.) and bumble bees (Bombus spp.) are the most common pollinators of this species in North America (Maddox et al., 1996; M. Sun, pers. obs.).

The plants also have a prolonged flowering period, from May to September in the Sacramento Valley, and May to October in San Diego (Beauchamp, 1986), although the flowering season is shorter in Washington and Idaho. Reproductive capacity is remarkable for this self-incompatible colonizer. An average of 267 capitula and over 10000 seeds per plant were recorded in a population in the Sacramento Valley (Maddox, 1981). Additionally, occasional breakdown of self-incompatibility occurs in some individuals of yellow starthistle, 
which can help ensure reproduction. Maddox et al. (1996) reported that a mean number of 27 seeds per capitulum was produced by a self-fertile yellow starthistle plant following experimental self-pollination. Mutation of incompatibility genes or at modifier loci is thought to underlie the loss of incompatibility (Barrett, 1988).

Variation of self-incompatibility would be evidenced by a significant estimate of the correlation of selfing, and/or significant variation of individual family outcrossing rates. For example, in the selfincompatible tree, Shorea congestiflora, family $t_{\mathrm{m}}$ was found to vary from 0.49 to 1.00 , and this perhaps resulted from weak self-incompatibility in some individuals (Murawski et al., 1994). We found significant correlation of selfing only in the Asotin population; estimates of individual outcrossing rates indicate that perhaps four families mainly contribute to this correlation (Fig. 1). The parents of these families may have reduced or lost self-incompatibility. However, population substructure, specifically the occurrence of more inbred genetic neighbourhoods, can also cause among-plant variation in outcrossing rate (Ritland \& Ganders, 1985). In the Asotin population, the seed collection came from a late-flowering patch, and thus seasonality caused by moisture availability may have contributed to a genetic neighbourhood (C. Roché, pers. comm.). It is also possible that self-incompatability may break down in late-flowering plants.

\section{Biparental inbreeding}

Nearly all the single-locus outcrossing estimates were significantly lower than the multilocus estimates, indicating biparental inbreeding (Ritland \& Jain, 1981). Such inbreeding is caused by the clustering of related plants combined with limited pollen flow. Indeed, C. solstitialis tends to form clumped, dense stands in some populations, and Roche (1991) found that the majority of seeds fell within $1.2 \mathrm{~m}$ of the source plant. Variation in the extent of population substructure and plant density might account for the observed differences in levels of biparental inbreeding among $C$. solstitialis populations. In selfincompatible populations of Helianthus annuus and Shorea species, increased levels of inbreeding were found at high plant densities (Ellstrand et al., 1978; Murawski et al., 1994). Such biparental inbreeding may be significant for the maintenance of selfincompatibility alleles in populations.

The occurrence of completely outbred $(F=0)$ parents in seven of the eight populations is somewhat puzzling in light of the biparental inbreeding rates. This can be explained by the presence of selection against biparentally inbred progeny, which can occur if genetic load is high.

\section{Correlation of outcrossed paternity}

Sharing of paternity within a family, as measured by the correlations of outcrossed paternity, $r_{\mathrm{p}}$, could arise from multiple deposits of pollen from a single male parent, or from mating to a small number of near-neighbours. The extent of correlated paternity between flowers of the same plant in Mimulus guttatus (20 per cent) was consistent with random mating to an effective pool of $1 / 0.20$ or five neighbours (Ritland, 1989). In our study, we found a similar effective mate pool, averaging 8.8 (calculated as the mean of the reciprocals of $r_{\mathrm{p}}$ in Table 2), although this average is highly affected by the San Diego population. If this population is excluded, the average number of mates increases to 9.8 .

In general, compared with outcrossing rates, estimates of correlated mating show more variation among populations. For example, the among-population variance of multilocus outcrossing estimates was 0.00027 (computed from Table 2), and this was about equal to that expected from random statistical error $(0.00032$, obtained as the mean variance of estimates). This indicates no 'actual variance' of outcrossing among populations. By contrast, the among-population variance of correlated paternity was 0.0354 , and the variance attributable to sampling error was only 0.0018 , indicating substantial 'actual variance' $(\approx 0.034)$ for correlated paternity. This indicates that correlated matings are potentially more illustrative of ecological factors. These factors include competition within pollen loads, fertility variation, phenological differences, pollen carryover and population substructure (Barrett et al., 1992).

\section{The marginal population San Diego}

Several lines of evidence indicated that a relatively high level of inbreeding and population substructure exists in the marginal population, San Diego. This population had the lowest $t_{\mathrm{m}}(0.948)$, the highest maternal inbreeding coefficient $(0.270)$, the highest correlation of outcrossed paternity (0.636) and a level of biparental inbreeding (0.095) nearly twice the average. This suggests the presence of small mating neighbourhoods that often consist of siblings. As this population apparently experienced a severe genetic bottleneck at founding (Sun, 1997), reduced allelic diversity at incompatibility loci may have also decreased the number of compatible mates in the 
neighbourhood. Finally, this population may have also lost some of its inbreeding depression, as the significant $F$ of parents indicates that selfed progeny have survived to maturity. However, it is not known whether current demographic factors may play a part in the higher amount of inbreeding in the marginal population, such as possible lower densitydependent selection against inbred progeny.

Selfing variants of normally outcrossing plant species are often found at the margins of their range (Lloyd, 1980). Gold Hill represents the northern limit of yellow starthistle's distribution in western North America, although this population occurs in an area with a history of yellow starthistle invasion (since 1928) and is not geographically isolated from other populations; no apparent founder effects were detected for either genetic diversity (Sun, 1997) or mating system parameters (Table 2). In contrast, the San Diego site, representing the southern distributional limit, is a geographically isolated, marginal population. High levels of inbreeding and correlated matings could have evolved following the founder event. The shift from outbreeding to self-fertilization has evolved repeatedly following colonization of geographically marginal habitats in Turnera ulmifolia and Eichhornia spp. (Barrett, 1989).

\section{Management implications}

Information obtained on the mating system of yellow starthistle is valuable to its management and control. The outcrossing system can maintain high levels of genetic variation within populations, which may contribute to colonizing success of the species. Biological control, which depends on the interaction of the host plant genotype and an insect genotype, may not be very effective in the case of yellow starthistle, because of its high level of diversity and/or potential for rapid evolutionary response. As the species is predominantly self-incompatible, pollinators are the keys to its reproductive success, and limiting pollination at the flowering season may significantly reduce seed output at the sites of invasion. In this light, commercial production of honey based on yellow starthistle plants, as frequently practised in the Sacramento Valley, California, might have contributed to its spread in the area.

\section{Acknow ledgements}

We thank H. Corke, C. T. Roché, B. F. Roché, J. Connett, J. P. McCaffery, C. D. Thomsen and D. Allen for assistance with seed collections; A. Lai for help with laboratory work; H. Corke and C. Roché for helpful comments and discussions, and $\mathrm{M}$. Pitcairn, J. Balciunas, J. DiTomaso, F. Ryan and colleagues in USDA-ARS and the University of California-Davis for reading an earlier version of the manuscript. This research was supported by a CRCG grant from the University of Hong Kong to M.S. and by an NSERC of Canada grant to K.R.

\section{References}

ABBOTT, R. J. AND FORBES, D. G. 1993. Outcrossing rate and self-incompatibility in the colonizing species Senecio squalidus. Heredity, 71, 155-159.

BAKER, H. G. 1955. Self-compatibility and establishment after 'long-distance' dispersal. Evolution, 9, 347-348.

BAKER, H. G. AND STEBBINS, G. L. (eds). 1965. The Genetics of Colonizing Species. Academic Press, New York.

BARRETT, s. C. H. 1988. The evolution, maintenance, and loss of self-incompatibility systems. In: Lovett Doust, J. and Lovett Doust, L. (eds) Plant Reproductive Ecology: Patterns and Strategies, pp. 98-124. Oxford University Press, New York.

BARRETT, S. C. H. 1989. The evolutionary breakdown of heterostyly. In: Bock, J. H. and Linhart, Y. B. (eds) The Evolutionary Ecology of Plants, pp. 151-169. Westview Press, Boulder, CO.

BARRETt, s. C. H. AND RICHARDSON, B. J. 1985. Genetic attributes of invading species. In: Groves, R. H. and Burdon, J. J. (eds) The Ecology of Biological Invasion: An Australian Perspective, pp. 21-33. Australian Academy of Science/Jacaranda Publishing, Canberra.

BARrett, S. C. H., KOHN, J. R. AND CRUZAN, M. B. 1992. Experimental studies of mating-system evolution: the marriage of marker genes and floral biology. In: Wyatt, R. (ed.) Ecology and Evolution of Plant Reproduction, pp. 192-230. Chapman and Hall, New York.

Beauchamp, R. M. 1986. A Flora of San Diego County, California. Sweet Water River Press, National City, CA.

BROWN, A. H. D. AND BURDON, J. J. 1987. Mating systems and colonizing success in plants. In: Gray, A. J., Crawley, M. J. and Edwards, P. J. (eds) Colonization, Succession and Stability, pp. 115-131. Blackwell Scientific Publications, Oxford.

BROWN, A. H. D. AND MARSHALL, D. R. 1981. Evolutionary changes accompanying colonization in plants. In: Scudder, G. E. C. and Reveal, J. L. (eds) Evolution Today, pp. 351-363. Hunt Institute for Botanical Documentation, Carnegie-Mellon University, Pittsburgh, PA.

BURdon, J. J., JAROSZ, A. M. AND BROWN, A. H. D. 1988. Temporal patterns of reproduction and outcrossing in weedy populations of Echium plantagineum. Biol. J. Linn. Soc., 34, 81-92.

CALliHAN, R. H., PRATHER, T. S. AND NORTHAM, F. E. 1993. Longevity of yellow starthistle (Centaurea solstitialis) achenes in soil. Weed Technol., 7, 33-35.

Ellstrand, N. C., TORRES, A. M. AND LEVIN, D. A. 1978. Density and the rate of apparent outcrossing in Helianthus annuus (Asteraceae). Syst. Bot., 3, 403-407. 
FRYXELL, P. A. 1957. Mode of reproduction in higher plants. Bot. Rev., 23, 135-233.

GLOVER, D. E. AND BARRETT, S. C. H. 1986. Variation in the mating system of Eichhornia paniculata (Spreng.) Solms. (Pontederiaceae). Evolution, 40, 1122-1131.

HAMRICK, J. L., LiNHART, Y. B. AND MitTON, J. B. 1979. Relationships between life history characteristics and electrophoretically detectable genetic variation in plants. Ann. Rev. Ecol. Syst., 10, 173-200.

KEPHART, S. R. 1990. Starch gel electrophoresis of plant isozymes: a comparative analysis of techniques. Am. J. Bot., 77, 693-712.

LlOYD, R. M. 1980. Demographic factors and mating patterns in Angiosperms. In: Solbrig, O. T. (ed.) Demography and Evolution in Plant Populations, pp. 67-88. Botanical Monographs vol. 15. Blackwell Scientific Publications, Oxford.

MADDOX, D. M. 1981. Introduction, phenology and density of yellow starthistle in coastal, intercoastal, and central valley situations in California. USDA-ARS, Agricultural Research Results, ARR-W-20/July.

MADDOX, D. M. AND MAYFIELD, A. 1985. Yellow starthistle infestations are on the increase. Calif. Agric., 39, 10-12.

MADDOX, D. M., MAYFIELD, A. AND PORITZ, N. H. 1985. Distribution of yellow starthistle (Centaurea solstitialis) and Russian knapweed (Centaurea repens). Weed Sci., 33, 315-327.

MADDOX, D. M., JOLEY, D. B., MAYFIELD, A. AND MACKEY, B. E. 1991. Impact of Bangasternus orientalis (Coleoptera: Curculionidae) on achene production of Centaurea solstitialis (Asterales: Asteraceae) at a low and high elevation site in California. Envir. Entomol., 20, 335-337.

MADDOX, D. M., JOLEY, D. B., SUPKOFF, D. M. AND MAYFIELD, A. 1996. Pollination biology of yellow starthistle (Centaurea solstitialis) in California. Can. J. Bot.,
74, 262-267.

MURAWSKI, D. A., DAYANANDAN, B. AND BAWA, K. S. 1994. Outcrossing rates of two endemic Shorea species from Sri Lankan tropical rain forests. Biotropica, 26, 23-29.

PANDEY, K. K. 1980. Evolution of incompatibility systems in plants: origin of 'independent' and complementary control of incompatibility in Angiosperms. New Phytol., 84, 381-400.

RITLAND, K. 1989. Correlated matings in the partial selfer, Mimulus guttatus. Evolution, 43, 848-859.

RITLAND, K. AND GANDERS, F. R. 1985. Variation in the mating system of Bidens menziesii (Asteraceae) in relation to population substructure. Heredity, 55, 235-244.

RITLAND, K. AND JAIN, S. K. 1981. A model for the estimation of outcrossing rate and gene frequencies using $n$ independent loci. Heredity, 47, 35-52.

RobBins, w. w., BELlue, M. K. AND BALL, w. s. 1951. Weeds of California. Printing Division (Documents Section), California State Department of Agriculture, Sacramento, CA.

ROCHE, B. F. 1991. Achene dispersal in yellow starthistle (Centaurea solstitialis L.). Northw. Sci., 66, 62-65.

STEBbins, G. 1957. Self fertilization and population variability in the higher plants. Am. Nat., 91, 337-354.

sun, M. 1997. Population genetic structure of yellow starthistle (Centaurea solstitialis), a colonizing weed in western United States. Can. J. Bot., 75, 1470-1478.

SUN, M. AND CORKE, H. 1992. Population genetics of colonizing success of weedy rye in Northern California. Theor. Appl. Genet., 83, 321-329.

THOMSEN, C. D., WILliAMS, W. A., GEORGE, M. R., McHENRY, W. B., BELL, F. L. AND KNIGHT, R. S. 1989. Managing yellow starthistle on rangeland. Calif. Agric., 43, 4-6.

THOMSEN, C. D., WILliAMS, W. A., VAYSSIERES, M. AND BELL, F. L. 1994. Yellow Starthistle Control. Range Science Report, no. 33. University of California, Davis. 